\title{
Preface to the German Edition
}

In Book 4 of the Iliad, after lengthy preliminaries, the actual fighting between the two enemy armies begins: the final third of the book contains the first battle descriptions in the Iliad. The complexity of the preceding storylines and of the portrayal of massed and individual fighting suggested that we should insert overviews in the commentary providing orientation $\left(t^{2} \mathrm{em}^{\mathrm{P}}\right.$ in the portrayal of the course of the battle and embedding within the larger action of the Iliad) and introductory chapters concerning the history of research on Homeric battle descriptions. For the purposes of the commentary, we have divided the Book among ourselves into three coherent individual sections: the divine scene/Pandaros (1219), the Epipolesis (220-421) and the beginning of the fighting (422-544).

As in previous volumes, the commentary is based on the Greek text of Martin L. West's edition of the Iliad (Bibliotheca Teubneriana, 1998/2000).

The realization and publication of this commentary was made possible thanks to important help and support from various sources:

First and foremost, we gratefully thank our esteemed teacher Prof. Joachim Latacz, who never tired of offering suggestions and assisting us up to the final version of the commentary. We are likewise grateful to Prof. Anton Bierl for his many suggestions and guidance in interpreting the text.

We also thank our international team of experts for valuable suggestions and corrections: Rudolf Führer, Fritz Graf, Martin Guggisberg, Irene de Jong, Sebastiaan van der Mije, René Nünlist, Magdalene Stoevesandt, Jürgen von Ungern-Sternberg and Rudolf Wachter. All of the above have once again facilitated our work with critical questions and suggestions. We thank Daniele Furlan for thought-provoking information regarding the driving technique of war chariots. In addition, we owe cordial thanks to our research assistants Luca Agnetti, Marie Besso, Doris Degen and Nathalie Reichel for meticulous proofreading, as well as to our colleague Claude Brügger for his assistance in producing and checking camera-ready copy.

We also express our gratitude here to the long-standing sponsors of the project for their generous support: the Schweizerischer Nationalfonds zur Förderung der wissenschaftlichen Forschung, the Hamburger Stiftung zur Förderung von Wissenschaft und Kultur and the University of Basel.

We are likewise grateful for the lively academic exchange we were privileged to take part in in the 'Rosshof', the Center for Classical Studies at the 
University of Basel, as well as in inter-university colloquia at Zurich and Basel in 2016. We thank the staff at the library for Classical Studies and the Basel University Library for the timely provision of scholarly literature related to Homer, and the publishing house Walter de Gruyter, in particular Katharina Legutke and Serena Pirrotta, for their careful management of the publication of these volumes.

Basel, March 2017 Marina Coray, Martha Krieter, Edzard Visser 